\title{
Microvita and Transformative Information
}

\author{
Marcus Bussey*
}

Sustainability Research Centre, The University of the Sunshine Coast, Queensland, Australia

\begin{abstract}
This paper explores microvita theory and its relevance to information science. There are two parts to this, the first is theoretical and outlines microvita theory as an epistemological product of the Tantric theory of consciousness and mind. The civilizational value of such a theory is contextualized via a consideration of Gilles Deleuze's concept of transcendental empiricism. Links to information science are made particularly with regard to Bates' evolutionary reading of information and to Dervin's sense making epistemological chronology. The second part of the paper explores microvita theory as an emergent possibility by profiling six developments in cultural practice. Each hint at the transformative possibilities before us when considering information from broader epistemological contexts than the given Western rationalfield we generally accept as the context for research. It is suggested that microvita theory invites in a shamanic disposition or temper which is comfortable with paradox and aporia. To navigate such terrain requires an appreciation for the spiritual within the working context of the world. The spiritual is taken as simply another form of data collection in a universe that is as mysterious as it is wonderful.
\end{abstract}

Key Words: Microvita, spirituality, information, Tantra, empiricism, sense making, agency.

...it was the sense that the whole universe was alive, and that everything was connected to everything else by threads of meaning [1, p. 473].

A vision of consciousness as endless, reflexive and alive sets the scene for this paper which explores Prabhat Rainjan Sarkar's microvita theory [2] and its relevance for information science. As this is one paper in a series dealing with Information and Spirituality I will move from a justification for such an exercise that might include assertions about intuition, psychic phenomena, spirits and spirituality, layers of mind, life after death and near death experiences, transcendent states, knowing and gnosis, social evolution, extracerebral memory, etc. to an overview of the ambitions of this paper. What can be asserted is that Microvita Theory is an emergent theory of consciousness that draws upon Sarkar's interpretation of Tantric metaphysics. His intention in doing this was to extend our western materialistic understanding of the world by informing matter and the cultural expressions built upon matter, including information, with consciousness [3]. As such this paper attempts the delicate balancing act of sketching out an innovation in the cultural field - a theory that spans both eastern and western conceptions of reality in order to augment both.

To do this I take a pragmatic view of information informed by Gilles Deleuze's concept of transcendental empiricism [4]. This challenges the epistemological distinctions between nature and culture, knowable and unknowable that characterizes positivist approaches to knowledge creation and suggests instead an interactive process in which the knower and the known are in a dialogical/dialectical relationship [5, 6]. Thus, as the physicist Michio Kaku notes, we

"Address correspondence to this author at the Sustainability Research Centre, The University of the Sunshine Coast, Queensland, Australia; Tel: +61 7 54594889; Fax: +61 7 54565008; E-mail: mbussey@usc.edu.au can be understood to inhabit a participatory and co-creative universe. Kaku concludes: "the universe does have a point: to produce sentient creatures like us who can observe it so that it exists" [7 p. 351]. In a similar manner, author Phillip Pullman notes in the opening quotation that we all inhabit a living universe in which everything is connected to everything else 'by threads of meaning'.

The paper falls into two parts. The first explores 1 . the theoretical context that grounds and contextualizes the theory of microvita; 2 . the ways in which this theory of consciousness can engage the field of information science. This is not a linear process but can be characterized as rhizomic [8]. Thus the following rhizomic pathway emerges: microvita theory is introduced, the epistemological context of Tantra is outlined, some links with information science are sketched and transcendental empiricism explored. The discussion then turns to an engagement with Dervin's sense making theory and explorations in reframing the civilizational context which currently determines how we approach questions of meaning, veracity and transformation. The section ends with a call for a shamanic temper in order to better negotiate the layers of reality microvita theory acknowledges.

The second part of this paper provides examples of how microvita can be understood as an emergent concept. This is profiled using Nicolescu's concept of transperception - the "global, non-differentiated understanding of the totality of levels of perception" [9 p. 99]. Different contexts are offered as examples of how microvita theory can be meaningfully applied to the analysis of and engagement in practical, speculative, creative and political contexts.

\section{PART 1: THE THEORETICAL CONTEXT}

\section{Definitions}

It is necessary to contextualise and define microvita as it is a term with emergent but as yet largely untested possibili- 
ties $[10,11]$. It was proposed as a theory of consciousness in the late 1980 s by the Indian mystic and philosopher Prabhat Rainjan Sarkar [2]. A largely enigmatic figure Sarkar straddles East and West as a polymath and controversial visionary. His life (1921-1990) brings into clear focus the fascinating dialogue that globalization has initiated between the 'West and the rest' as he fuses in his social and philosophical work concepts previously contextualised within discrete civilizational processes. So, as Inayatullah observes, Sarkar exists both in Modernist time as philosopher and social activist and outside time (in eternal time) as guru [12 p. 1-2]. Sarkar brings to a discussion of information the interpretive lens of Tantra. It is Tantra that supplies the context for understanding microvita.

Epistemologically Tantra is a dialectical and process oriented position that situates sense making in the between that is so often overlooked in our dualistic European culture whose geophilosophical understanding of reality is heavily shaped by Judeo-Christian traditions [13, 14]. It has much in common with Dervin's definition of sense making within information science:

"Sense-Making thrusts itself between chaos and order, structure and person, facts and illusions, external worlds and inner, universals and particulars. Sense-Making posits reality as ordered in part, chaotic in part, evolving in part [15 p. 730].”

Tantra largely agrees with this reading thus Sarkar approaches reality as multiple: "the real is physical, mental and spiritual" [12 p. 8]. In some respects this correlates with Kari and Savolainen's contextual model of information [16] where life-worlds push thinking about information from 'narrow band' concerns to considerations about the 'more intangible qualities' of life [16 p. 156]. Furthermore, it extends the evolutionary possibilities that Bates explores in her quest for an evolutionary model of information [17]. However, for Sarkar the focus is on transformative possibilities within context as revealed by the ontological trajectory of consciousness across the material-mental-spiritual domains of human existence. Such considerations are absent from Bates' speculations as she is wholly focused on the human 'animal', arguing that "no abstract plane is assumed to house or manifest the information associated with the physical realities we experience."

In Tantric discourse it is consciousness not humanity that holds centre stage. Information, from this perspective moves across a spectrum that includes everything from passive data (Bates' Data 1) to transformative memes. Tantra has been traditionally associated in the West with exotic and often sexual practices [18]. It is however much more than this derivative form and offers an inclusive vision of reality that accounts for individual and collective evolution as an ongoing expression of consciousness in dialogue within its multiple forms $[19,20]$. This dialogue is often fraught with struggle and paradox yet informs both individual and collective expression with a sense of depth and meaning that empowers individuals and collectivities with a sense of purpose and supplies conceptual tools and also physical and spiritual practices to engage more fully with the life-world.
Microvita is one such tool. The term means micro $=$ small $+v i t a=$ life. For Sarkar microvita are essentially the building blocks of the universe. Much smaller then atoms, they are the vibrational bridge between the non-physical and matter. Modern physics is exploring the nature of reality as vibrational energy fields - here we find quarks and dark matter at work in quite mysterious ways.

This is a contested field, and still marginal within the dominant paradigm of scientific orthodoxy which remains resolutely materialist. Yet scientists such as Towsey and Ghista challenge this paradigm and argue that mind and consciousness are much more than epiphenomenon of the physical world $[3,10]$. The vibrational quality of matter points towards nascent consciousness that require of the observer subtler modes of consciousness in order to perceive it. Thus we find scientists acknowledging that much of this work requires intuitive reasoning based not on direct material evidence but on the effects of these propositions [7, 21, 22].

Similarly Sarkar argued that microvita could only be recognised by highly developed intuitional minds who account for such subtle phenomena via their effects [2]. He advocated mediation to develop intuitive power and the sensibility required to observe consciousness at work in matter. Thus he suggests microvita as a form of cosmic intelligence at work throughout the entire universe. As Gautier notes:

"Microvita, as mediators of cosmic intelligence, are responsible for the creation and evolution of other living beings in the universe, and the formation of the chemical elements as well. Microvita move unbarred through the physical universe, and some can travel through the medium of mind as well [11 p. 169]."

Sarkar's (1991) overview of microvita is couched in Sanskrit terms and highly speculative. He argued that the concept was emergent and would take centuries to be clarified. In the scientific arena much needs to happen in order for any clarity to be reached, as such it should be considered a weak signal flagging a possible development inherent to epistemological encounters across civilizational and temporal space. However, he did describe features of microvita that were already intelligible to us, or would be so in the near future.

To begin with, we can say that microvita are:

- A new way of understanding consciousness

- Living entities, thus they follow the standard life cycle

- Perceived inferentially, i.e. by their effects

- Sub atomic but varies greatly in size

- Either negative, positive or neutral in effect

- Found along a continuum, with the crudest being viral in nature (and behave so); the subtlest are ideas (and act as such)

- Vibrational not concrete (perhaps like crystals or fractals)

Now this last point indicates that microvita are self organizing. Consciousness in Tantra is understood as pattern that oscillates at a frequency and reflects levels of complexity [23]. Microvita move across these levels and become 
more complex and more subtle, or less complex and less subtle according to context. They attract consciousness and on each encounter become something new. Thus microvita can be understood as fluid, hybrid, perhaps even fractal. They seek order amidst disequilibrium but order is always illusory rather than absolute. Hence Towsey and Ghista argue the dynamic of instability within order (entropy) is such that evolution from matter to consciousness relates to increasingly complex systems in which we move from selforganisation to self-realisation with its concomitant selfawareness. This implies the ever present possibility of consciousness in all matter and suggests a theoretical basis for microvita within the physical sciences [10 p. 343].

\section{Microvita and Information Science}

In the context of information science the concept of microvita can be seen to expand and deepen the information continuum described by Kari and Savolainen [24]. Such a deepening will be discussed below. Furthermore, it relates to the understanding of information offered by Bates [17]. Following Parker [25] she describes information as the "pattern of organization of matter and energy". She develops this concept to include both physical pattern and emergent pattern. She keeps her focus on process and thus avoids being trapped by a specific definitional position. For her the world is information-rich and can be best read in evolutionary terms as a process oriented experience of reality which is formative and open ended in nature.

"In information terms, an information-rich world is one in which there are many variations from pure chaos or entropy, i.e., where there are many regularities, differentiations, bunchings and clusterings of matter and energy. [17 p. 7]."

This definition reminds us of Floridi's 'fully tessellated infosphere' [see 26 p. 557]. As Herold [26] points out, an information rich world is not the world in itself. It is the product of human engagement with the world. Information emerges from relationship with context. Latour similarly argues, via actor network theory, that information emerges in networks of activity that generate the schema's for lifting information into focus, beyond data and the white noise of the infosphere [5]. Such schemas are cultural patterns that help us select, bunch and cluster Bate's matter and energy (aka data) into meaningful chunks.

Such thinking is in line with Sarkar's microvita theory in that microvita form patterns in energy - whether physical or mental or spiritual - and these can replicate or die out over time, they can hybridize and metamorphose, they can move from simple to complex and from complex to simple [2]. According to the complexity of the pattern microvita can be understood as raw data, more refined (ie filtered) information, or as knowledge.

Microvita theory also allows us to rethink the relationship between individual and collective, the agent within the context of an ever flowing, permanently in flux infosphere. It allows for a dynamic relationship with meaning making and the way information is understood within context. The focus of much research in information studies, as Kari and Savolainen (2007) point out in their examination of the uses of the WWW, has been on narrow band issues such as seeking, task, situation or person. Because microvita accounts for both the 'white noise' of background context, the data from which information emerges, as well and the role of consciousness in the development and maintenance of context, the questions and concerns shift towards holistic and metaphysical concerns pertaining to order, chaos, hybridity, and the challenge the spiritual poses to normative assumptions about the real and how information might function in it.

Part of this shift is in the reconceptualization of the individual - or more specifically the reconceptualization of parts in relation to wholes. The theory suggests that parts only exist because of their relationship to wholes. Now there are contexts in which parts and wholes behave according to specific rules: the universe is governed by the rules of physics and these rules are played out on its constituent parts; the planet is constituted by a range of spheres (biosphere, hydrosphere, infosphere, etc) and these all apply rules and meaning to the constituent parts; a nation is organized around laws and customs and its citizens draw meaning and identity from these; an institution too is a composite of purpose and a mores or ethos and meaning and purpose are drawn from these.

\section{Shifting the Emphasis}

Thus we can see that at the existential and phenomenological levels microvita theory shifts the emphasis from the individual developing autonomous Self (upper case is intentional) to the individual developing collective self. This generates what Herold [26 p. 557], following von Foerster, calls a relational data base from which the 'collective individual', if self aware, is able to observe and interact with the collective consciousness of any social structure in such a way that their independence and power is maintained yet their sensitivity and connection to the collective process is not lost. Such an individual has within their power the ability to act upon the dominant microvita of an institution in order to bring about constructive change.

In such contexts information can be highly influential in bringing about change. This is because it is no longer simply an epiphenomenon of context but a charged and vibrationally alive unit of energy consciousness. No longer is it neutral or passive. Context itself and the dynamic interactivity of the minds in situ bring a range of readings to bear. Sarkar [2 p. 43] points out that at some point in the future we will be able to read microvita in such a way that it can be measured. Thus a unit of information may be charged in some way we are yet unable to read. Yet it can be understood by its effect. For example the name Allah might bring anxiety to a resident of New York and elation to a resident of Mecca. The context, of course, determines the reading but the use of the word - the intent links up and releases specific vibrational responses that emerge out of the microvital field.

The question of intent indicates that consciousness is always implicit in information and its uses and abuses. The purpose of any inquiry into information at a spiritual level suggests that we need to turn our attention to the deeper issue of consciousness as interlocutor with context [27]. Spirituality is a way of understanding Being that reaches beyond the forms of the material expression of the Universe to incorporate atemporal, ideative and immutable conditions. Yet it acknowledges the physical grounding for all such considera- 
tions and demands of us that we engage in deepened critique - what Giri [28 p. 5] calls 'spiritual criticism'. As a form of practical spirituality we then can understand critique as a way of moving beyond what Bourdieu [29 p. 184] called habitus in order to practically shoulder our collective responsibility to context. Vivekananda summed up such a requirement when he declared:

"The watchword of all well-being, of all moral good is not 'I' but 'thou'. Who cares whether there is a heaven or a hell, who cares if there is an unchangeable or not? Here is the world and it is full of misery. Go out into it as Buddha did, and struggle to lessen it or die in the attempt [cited in 28 p. 5-6]".

To transcend habitus and engage a grounded spirituality that has critical force calls for a reading of consciousness that incorporates the relational nature of meaning generation. The standard representation of data-information-knowledgewisdom (DIKW) as a hierarchy only partly suggests this [30]. Sarkar [2] proposes that microvita exist along this continuum and that the human being can engage in a range of spiritual practices and disciplines that enable access to and engagement with these fields of activity: the field of data (raw existence or litany), the field of information (system/structure and the domain of habitus), the field of knowledge (worldview and paradigm) and the field of wisdom (integrative Being that works with metaphor and causal mythic process) [31].

Microvita, as modes of conscious organisation, respond to consciousness and the reverse also holds. Consciousness when caste as a spiritual engagement with context becomes a medium for engaging with the world in such a way that information expands to incorporate Floridi's [32 p. 560] three perspectives on information 1 . reality, 2 . about reality and 3 . for reality, to also include a dialectical relationship in which both reality and agent play with one another. This 'play' is essentially ideational in nature and is realised as a political and ethical project across the domains Floridi identifies and the DIKW describes. It calls forth a specific kind of consciousness that interacts with reality for the all round development of its possibilities [33]. Such a project highlights the critical role information has in the broader libratory agenda of spiritual activism. Microvita theory brings to information science the paradoxical mixture of a transcendental reading of reality with a commitment to the grounded and unique nature of context. Deleuze [4] establishes the philosophical foundations for such an epistemological shift by proposing a transcendental empiricism.

\section{Transcendental Empiricism}

A transcendental empiricism needs to be approached with some caution. Much depends, however, on this idea. Empiricism has long been the ground for solid, rigorous and authoritative science. Of course science and scientists have changed over time in response to the world and the information flows that have been navigated. Scientists $[34,35]$, well some of them anyway, are now less enamoured of their method and more willing to acknowledge a range of possible post-normal scientific arrangements.

Smith [36], for instance, sees post-normal science as being part of an 'evolution of scientific process' in which rigor is maintained but allowance is made for uncertainty, the value positions of the researchers and for participatory encounters in knowledge formation. Deleuze allows us to read such an extension as a form of dialogical empiricism. Empiricism, Deleuze and Guattari assert, "knows only events and other people" [37 p. 48] yet, they argue, both events and people are multiple, being in a constant process of becoming. This becoming is contextual, occurring in dialogue with site or what Deleuze and Guattari call the plane of immanence. Empiricism thus invokes the 'and' in relation to the becoming-subjects' experience of the outside/real. This 'and' reminds actors that there is always something immanent, awaiting emergence from the plane of context. Thus the subject's story is never complete, never whole: hence we are always becoming [8 p. 6ff]. The plane that grounds such becoming is multiple and fluid. The real is never stable nor as it appears. There is a non-personal and intra-cultural dimension involved with the practice of reality. Information, in this reading, becomes streams of possibilities coursing across a domain of becoming.

Such a perspective allows us to see that the act of accessing information immediately alters both the researcher and the information. Consciousness becomes its own reflexive process and yet, Deleuze is insistent, this must be grounded and not shaped via an a priori assumption of ideology as lens. He works across concrete domains as a pragmatist who understands reality as self referential in the sense that Kaku [7] implies. Thus both the universe and its observer come, as the result of reflection, into existence. Therefore Deleuze argues in the Logic of Sense "Only empiricism knows how to transcend the experiential dimension of the visible without falling into Ideas, and how to track down, invoke, and perhaps produce a phantom" [cited in 38 p. 34]. This makes the DIKW hierarchy fraught with contradictions - the first being that there is some kind of linear process at work in ordering meaning.

By challenging such a hierarchy Deleuze frees empiricism and the act of information gathering from direct environmental conditioning - a grounding that is always suspect for being absolute - and the patterns of knowing grounded in the energy flows that Bates refers to. This is the transcendental quality of Deleuze's understanding of empiricism and has direct implications for how microvita can be applied to our understanding of information. Deleuze and Guattari (1987) discuss rhizomes at length in an attempt, via analogy, to capture the processes at work on context.

Microvita behave rhizomically as streams of consciousness, vibrational nodes, data entry and exit points that construct any representation of reality. They can be accessed empirically by studying their effects. Sarkar asserts they are part of the physical universe, they are simply as yet obscured by the crude methods we bring to bear in our empirical engagement with context. While quantum physics is making headway, the idea also requires a shamanic disposition to open up context to subtler readings of process [39]. This transcendental dimension of empirical process is simply an expansion of the human quest for information on their world. Semetsky sums up this apparent paradox:

"Deleuze's method remains empirical by virtue of the object of inquiry regarded as real, albeit subrepresentative, 


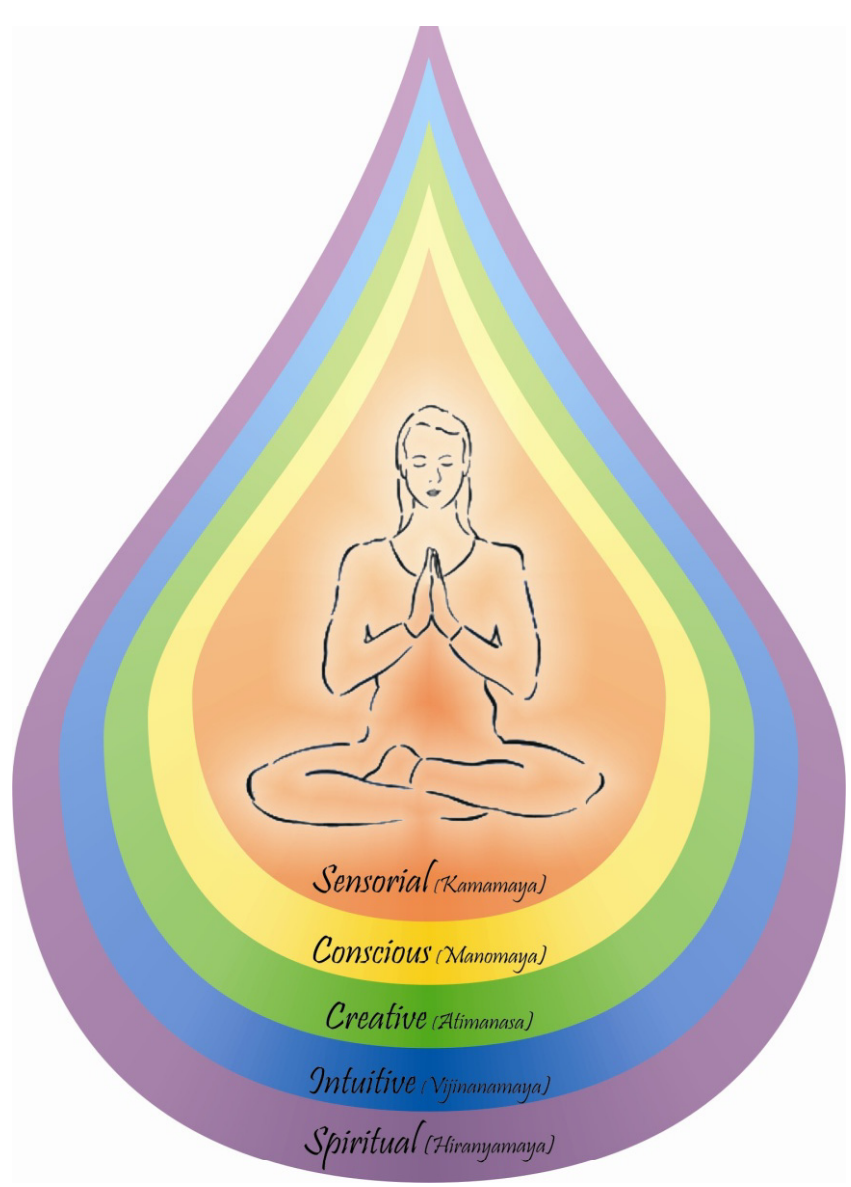

Fig. (1). Expanded vision of mind.

experience. Yet, it is also transcendental because the very foundations for the empirical principles are a priori left outside the common faculties of perception [38 p. 34]".

The context Deleuze describes is open ended. It is also multi-tangential, i.e. rhizomic, in that depth is understood as inherent to context but not structured around any particular axis. Layers therefore are not so much structural - as in the onion for instance - but trans-structural. Microvita flow across such layers and bring meaning and substance to our experiences. The real is now not only the physical universe which surrounds us, nor is it simply the product of our reflective engagement with time, place and space but rather it is an extension of the perceptual field to inference and vibration which is supra-physical.

\section{Transformative Knowledge}

Microvita theory invites in the spiritual domain to any full theory of information science. It greatly extends the categories of the real to incorporate what Inayatullah describes as the "non-local field of awareness that makes sense of reality" [40 p. 6]. It does so by offering a transcendental empiricism akin to Deleuze but grounded in the Tantric metaphysics of Sarkar's ontological orientation. Sarkar had a knack for neologisms. Each new term he developed with conscious historical and cultural referents. Microvita evokes the vitalist theory by suggesting a dimension to life that lies beyond biological explanations [2 p. 89ff]. Yet it escapes the need vitalists felt to demonstrate the truth of this insight within the mechanistic scientific frame work of scientific thought. This side stepping is not a slight of hand, or the result of 'lazy thinking' but due to the fact that its core assumptions about reality come not from the Graeco-Roman scientific tradition but from the Tantric tradition of India.

The Tantric theory of mind pushes beyond the biological and cultural understanding that drives Bates' evolutionary analysis (2005). It also reframes the contextual map offered by Kari and Savolainen [16]. Instead it allows for structure (biological and institutional) post-structure (cultural and epistemological) and trans-structure (spiritual and causal) as dimensions of reality. The model of reality proposed by Tantric theory allows for a range of information to be accessed by the human mind. This vision offers an expanded field of perception via an expanded conceptualization of mind (Fig. 1 with Sanskrit terms). The physical senses of the nervous system discern physical Data; the intellect discerns via analysis and synthesis (Information and Knowledge); the subtle mind discerns via creativity, intuition and meditation (Wisdom). Sarkar argues that inference is a function of the superconscious mind. The superconscious mind, he states, is accessed and developed via discipline (creativity), presence (intuition) and meditation (spirituality) [41].

Microvita are very subtle and do require the development of the layered consciousness described here. But they are not restricted to the spiritual, as in the traditional western metaphysical category we commonly use. From the Tantric perspective there is no separation of states, they are simply manifestations of consciousness bound by various organizing forces described in Sanskrit as gunas. The gunas are a way of thinking about the world as composed of static, mutable and subtle energy patterns. According to context one or other of these states dominates so we have a nested reality at work in which human consciousness engages with the world around it in ways that read these states as physical, dynamic and spiritual. The correlation, however, is relative. Inferential thought, the kind of thinking-sensing that can access spiritual information is always bounded by the relativity of context, yet it also demands of those working the field to use inferential language that supplies approximations to what is experienced.

\section{Deepening Context}

It is time to look more deeply at what a concept like microvita brings to our understanding of information. This can be done with reference to Kari and Savolainen's [16 p. 158] contextual model of information seeking on the world wide web (WWW). Here, in Fig. (2), they describe a nested series of 'processes in which the actor participates'. Each can be read as a determining/limiting factor - a meaning making structure - of how information is sought. The authors explicitly state that 1 . they are attempting to take into account the entire 'web world' of an individual seeker; 2 . that they are not taking into account what the person does not know or is unconscious of [16 p. 166]. Such a meta context, the unconscious-unknown, they do not see as a determinant in practical terms for a holistic conception of seeking on the WWW.

As a map of the realms of activity and intention Kari and Savolainen's contextual model (Fig. 2) works effectively. It 


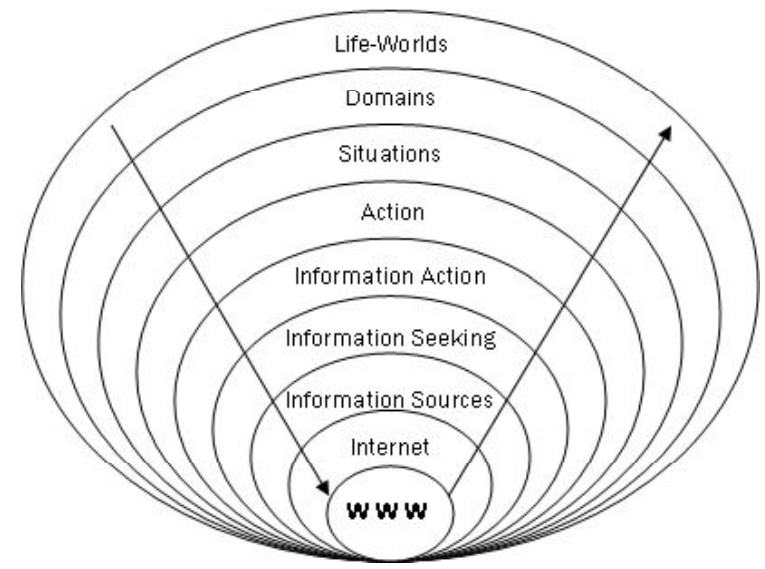

Fig. (2). Kari and Savolainen's (2003) contextual model.

also allows for researchers to identify areas they may wish to interrogate. However, it leaves largely unaddressed the relationships between or, as Deleuze might say, across these realms. This gap is quite literally alive with possibility. Microvita move across this domain, forming, morphing, hybridizing constantly. The theory provides another lens for understanding the process orientation of models.

For instance we can now consider the Web as a form of and conduit for microvita; the web also provides new contexts for microvita to connect, hybridize and leap across boundaries; the distinction between virtual and real on the Web breaks down - microvita theory reads the world holographically so reinforces this conflation [21]; the nature of mind accessing the Web determines its possibilities - the more subtle the more likely the WWW will be directed to expansive and transformative information generation; microvita constructs meaning as patterns of energy flow, and the Web can be seen to facilitate this ordering of reality; microvita behave virally and again the Web facilitates this behaviour and also models it (reflexive relationship); the Web creates its own meaning context, it is an emergent microvital field.

Such considerations deepen our thinking about information use. They point to creative disjuncture and chaos as the underpinning of reality. Culture, human consciousness, habit, information and knowledge become the defences against this forbidding context. In Deleuze and Guattari's [37] world this is all about the human struggle to tame and frame the chaosmos. In Sarkar's reading it is all about the dynamic tension between consciousness (freedom from context) and ignorance (being captive to context) [23].

\section{Riding Chaos}

Dervin [42] provides an elegant pathway through this messy field by proposing eight historical narratives that describe the unfolding human relationship with information design. Here she describes the shift in scholarly attention away from order towards an acceptance that order is relative and always at the mercy of entropy [see also 43]. The eight steps are as follows

\section{Information describes an ordered reality}

2. Information describes an ordered reality but can be 'found' only by those with the proper observing skills and technology
3. Information describes an ordered reality that varies across time and space

4. Information describes an ordered reality that varies across time and place

5. Information describes an ordered reality that varies from person to person

6. Information is an instrument of power imposed in discourse on those without power

7. Information imposes order on a chaotic reality

8. Information is a tool designed by human beings to make sense of a reality assumed to be both chaotic and orderly [42 p. 37-39].

We can see the epistemological terrain moving from the security of an Enlightenment rationality, through disciplinary knowledge, to increasingly less stable configurations affected by existential angst and phenomenological sensitivity, to poststructural attacks on the links between power and knowledge, and finally to a pragmatic acknowledgement of the use value of a tool in an uncertain world.

Yet this trajectory has not ended, nor does Dervin claim it has, as we are now contemplating information and its relationship to spirituality. This shift, as with the other shifts described by Dervin, hinges on how we understand the human condition and what it means to be human. As noted earlier how we are constructing reality civilizationally is altering as philosophical currents are hybridizing as a result of globalization. Similarly, science itself is facing a post-normal future and many creative scientists are considering various modalities for understanding depth [34, 44, 45]. This all points to another qualitative shift in how we think about information. Perhaps we could add a ninth step to Dervin's sense making, one which links more 'sense' with more 'information'.

9. Information is a product of consciousness: expand our understanding of consciousness and we expand the information available to us.

\section{Reframing}

This process of expansion is dynamic and moves us away from the Western approach to knowledge production as ordered. It brings it alive with a dynamic energy that breaks away from the rational mind. To engage with Chaosmos requires new skills and a new temper: one which draws on the multi-civilizational world emergent in the cultural encounters of the twenty first century.

This new temper can be understood as shamanic [39] and requires new ways of understanding process, especially as a spiritual energy that underwrites consciousness. Sarkar, whose work on microvita engages with this emergent insight, reminds us that when talking about spirituality we will struggle without developing new conceptual and linguistic resources. Microvita need to be approached via metaphor, symbol and analogy. The kind of perception needed to address such an idea needs, according to Sarkar, to be "conveyed with immensely suggestive language, hence the custom of conveying ideas symbolically" [2 p. 92]. The concept sets the stage for engagement with a less ordered reality, the choasmos, which is creative, dynamic, unstable and com- 


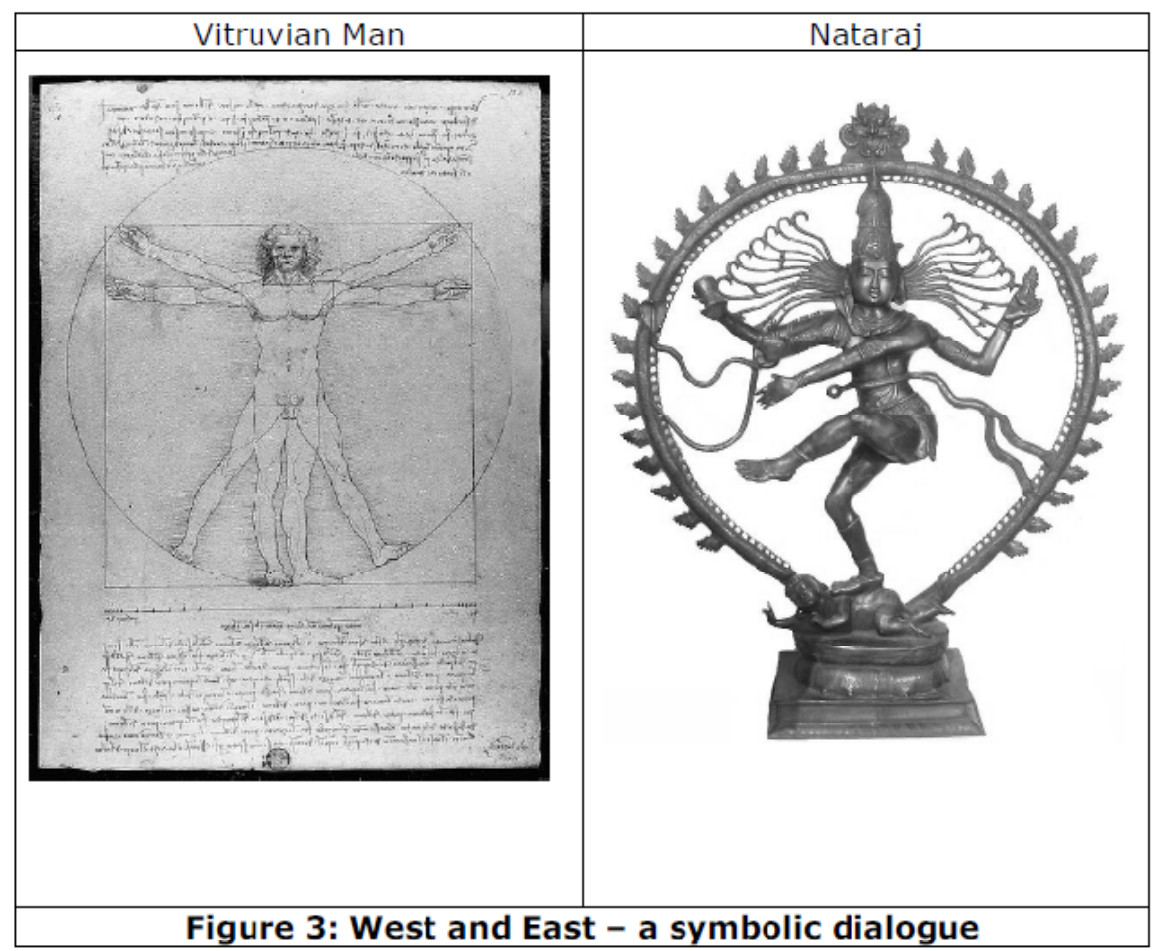

Fig. (3). West and East - a symbolic dialogue.

plex. Microvita theory begins a new thread in what is already an ongoing conversation across the disciplines. The concerns it seeks to address are emergent trends within disciplinary structures that are struggling to shape conceptions to account for increasingly ill fitting 'data sets'.

If we seek to understand this shifting terrain it helps to look for symbols that visually capture the new informational possibilities before us. The Western quest for order for instance is captured beautifully by Leonardo da Vinci's Vitruvian Man, while the Tantric idea of a dynamic and chaotic Cosmos is beautifully expressed in the dancing figure of the Nataraj (Fig. 3).

Understood civilizationally, these two figures can now be read as in dialogue. Both offer important insights. The trick is to capture the potential for the encounter to release dynamic new insights into human possibility. Greene sums this up well when she observes:

"The problem for us is to internalize what we have learned, to resonate to it and the works offered to our attention, and then to effect - slowly, perhaps- a kind of transformation [46 p. 70]".

Or, in a more poetic mood, the American poet Wallace Stevens put it like this:

"Throw away the lights, the definitions, And say of what you see in the dark."

"That it is this or that it is that, But do not use the rotted names".

"How should you walk in that space and know Nothing of the madness of space,"
"Nothing of its jocular procreations? Throw the lights away. Nothing must stand"

"Between you and the shapes you take When the crust of shape has been destroyed. You as you are? You are yourself. [47 p. 183]".

When we throw away our definitions and stray into the dark unknown our dormant senses need to be developed. As we throw out the 'rotted names' and employ new categories ('jocular procreations') there is a strangeness to it all. To engage the superconscious mind is a creative, intuitional and spiritual task. This is the task of the modern information shaman: a being who accesses information not simply as data but as transformative signals.

\section{PART 2: PROFILING TRANSPERCEPTION}

The encounter between different levels of Reality and different levels of perception engenders different levels of representation. Images corresponding to a certain level of representation have a different quality than images associated with another level of representation, because each quality is associated with a certain level of Reality and a certain level of perception. [9 p. 99].

The theory of microvita suggests that a deepened engagement with reality is possible and also verifiable if we know how to look for it. Nicolescu, a theoretical physicist, argues in the quotation above that for emergent physics there is a layered reality and that our perceptual tools need to change in order to read each layer effectively. This shift, as noted at the beginning of this paper, he calls 'transperception'. The spiritual worldview of Tantra takes a similar stance. Such change always start at the fringes [3, 37 p. 108, 
48 p. 15] but already the signs are that subtle mind is being linked with dominant discourses as diverse as agency, science and consumerism. They are also emerging in literature, the visual arts and transforming the politics of liberation.

The importance of microvita theory in information science is that it is flagging a new literacy that requires a new perceptual mode. Microvita theory implicates individual and collective consciousness in reality at all levels. It points to a new pedagogy or awareness based on a transcendental empiricism that values intuition, transperception and spirituality as modes of informational scaffolding and acquisition. Each of these assertions will be profiled here.

\section{Agency}

Inayatullah (2008), as Professor of Futures Studies at Tamkang University, Taiwan, Adjunct Professor at the University of the Sunshine Coast, Australia and in his association with the executive education programme at the University of Melbourne's Mt Eliza Business School, has been working as an advisor to government, non-government and corporate groups for over two decades (see his www.metafuture.org). He has introduced to his work the ideas of Esther and Jerry Hicks [49], Hal and Sidra Stone [50] and Eckhart Tolle [51]. All these writers bring both a conceptual and vibrational depth to context. One example of this is in the use of the concept of alignment. This concept has multiple referents: it can refer to timing the future as in bringing self and organization into alignment with emergent processes that bring greater energy, productivity and meaning to context; it can refer to aligning day to day goals with strategy, and strategy with big picture and big picture with vision and vision with the day to day; it can also refer to aligning inner and outer both at the personal and institutional levels. In all cases alignment can be understood microvitally as getting clarity at the vibrational level and minimizing points of energetic resistance.

The spiritual quest brings to this work an increasing capacity to align mind - physical, thinking and causal - with one's context. This happens because mind is understood vibrationally as a microvita transmitter-receiver that both orders and is ordered by context. A spiritually developed mind, this is not about enlightenment but simply a mind exercised and expanded through regular spiritual practice such as meditation, is more aligned with the microvital ordering of context. Such a mind picks up information intuitively and generates outputs that engage with reordering. Such a mind exudes microvita that acts as a solvent and reorders possibilities. The Dalai Lama is a good example of this at a global level. He is working on deep alignment and knows that linear time is not the issue for Tibet but long range time. Another example globally is the resurgence of indigenous power in the form of an 'indigenous modernity' [52] that steps outside of linear, strategic time and reorders the collective consciousness.

This is not information as data or even knowledge, it is information as patterns of meaning making and involves a metaphysical, or transperceptual dimension often left out of strategic thinking about context and the possibilities inherent to it. As Inayatullah is demonstrating through his work when we expand our definition of culture and deepen our under- standing of context by introducing the concept of microvita and expanded mind, a whole range of new possibilities in the field of information generation emerge.

\section{Science}

Sheldrake [53] wrote about morphic resonance two decades ago. In this work he posited a field of extended consciousness that lay beyond the local consciousness of mind, the local energy field in non-cerebral beings such as plants and the physical energy fields of inanimate matter. His concept has always had strong parallels with microvita theory. Recently Sheldrake has been studying the 'seventh sense' and the 'extended mind'. Here he questions materialist scientific thought that claims that our consciousness is an “"epiphenomenon' of brain activity" [45 p. 13]. He offers an extended picture of the mind, arguing that traditionally our senses have been corralled through conditioning into the five standard senses. To challenge this he posits a seventh sense "a kind of sensory system over and above the known senses, but a sense just the same" [45 p. 4].

He marshals considerable quantities of empirical evidence to establish the function of this mind as an extended sensory process in which the "mind stretches out through mental fields" [45 p. 16]. Such a concept has similarities with the Tantric concept of mind offered earlier in this paper. Sheldrake acknowledges that such awareness is part of many indigenous wisdom traditions [45 p. 15]. He does not link these fields to either the spiritual or supernatural, but argues for extended consciousness. Sarkar [2] has argued that though microvita are more easily discerned via subtle mind they are still living entities governed by natural laws. The 'spiritual' involved in this context is simply the tuning of mind via processes culturally interpreted as 'spiritual' such as meditation and Zen presence.

Sheldrake's evidence for extended mind is impressive and enables valuable comparisons to be made between a theory of morphic resonance and that of microvita. The fields Sheldrake describe are general and yet attract or repel according to frequency. Microvita can be understood to behave similarly. Sarkar discusses at length how certain minds and kinds of group consciousness attract microvita that transform context. He [53] extends his argument however to suggest that powerfully developed minds can transmit and attract different kinds of microvita which inform personal and cultural space in ways that also initiate transformation. In this he brings a critical sensibility to bear while Sheldrake remains focused on the science.

\section{Consumerism}

Sarkar (1991) speculated over twenty years ago that products are not products. The same item may have significantly different amounts of positive microvita and thus have greater or lesser impact on a consumer's health and well being. This idea is now moving mainstream with Time Magazine running a report [54] on 'embedded foods' that their manufacturers say will make us happy! They introduce a range of products such as $\mathbf{H}_{\mathbf{2}} \mathbf{O m}$ and Intentional Chocolate.

Since 2006, California company $\mathbf{H}_{2} \mathbf{O m}$ has sold water infused with 'love', 'joy' and 'perfect health' via the words, symbols and colours on the label (which 'create a specific 
vibratory frequency' according to co-founder Sandy Fox) and the restorative music played at their warehouse.

Intentional Chocolate founded in 2007 by chocolatier Jim Walsh, uses a special recording device to capture the electromagnetic brainwaves of meditating Tibetan monks; Walsh then exposes his convections to the recording for five days per batch [54 p. 35].

Intention is being linked to the ambient effects of a product. This might be considered a fiendish ploy on the part of capitalists to harness the untapped market of soft headed New Agers who are always looking for new ways to feel good about excessive consumption but it simultaneously flags the emergence of a new and powerful reading of reality. Time Magazine of course supplies the mandatory scientists for and against such a proposition. But when science is about worldviews we are left to consider the findings of the scientist Dean Radin from the Institute of Noetic Sciences who:

"conducted tests in which, he says, subjects who ate Intentional Chocolate improved their mood 67\% compared to people who ate regular chocolate [54 p. 35]".

"The article's author Alana B. Elias Kornfeld is open to the idea and concludes that:

Gimmick or not, in this economy any product that promises a spiritual pick-me-up could be in high demand [54 p. 35]".

This is a significant development as it links both science and the economy in a project to measure the intangible and market it. Microvita are one name for the 'vibrational frequency' and the 'electromagnetic brainwaves' referred to here. The imagery carries interesting correlations with Bates' definition of information as energy patterns. In this context intention, meditation and positive outcomes are linked in a populist reading of 'good vibes' and yet the message is clearly resonating that the inversion of common sense, that is inherent to the shamanic approach to transformation, is being played out in the theatre of the market.

\section{Literature}

Popular fiction has often been ahead of science. In this way informed intelligence freed from the constraints of a particular discipline can glide effortlessly over the practicalities of the science and leap upon an idea - thus we have Jules Verne's time machine and Isaac Asimov's robots. Various aspects of microvita have also appeared in creative work such as the novels by Isobelle Carmody and Philip Pullman.

Carmody's [55] Obernewtyn series posits a range of extra sensory phenomena as a ground for her elaborate stories. But it is in Pullman's [56] His Dark Materials trilogy that we have the best example of microvita I have yet found. In these novels Pullman talks about 'dust' as a manifestation of consciousness. Pullman draws on new physics to propose alternative realities and he moves his characters effortlessly between these. His description of dust is so evocative of the approach Sarkar has taken as to be breath taking. He links dust, also at times in the novels referred to as shadows, to adult consciousness and the awareness of good and evil; he uses the Chinese book of the I Ching as a corollary for this dust. Pattern in Pullman's thinking, as read by the I Ching, is important as consciousness has pattern- like Bates' definition of information - and suggests that this virtually invisible substance is the product of consciousness and desires to communicate with other conscious beings; then he proposes that dust is being sucked out of the world and that this is dangerous as it is consciousness that underwrites meaningful reality.

Pullman draws on eastern metaphysic, western geomancy and quantum physics in an intuitive way to weave new forms for understanding and engaging consciousness (dust). There is an implied unity to his work in which activated consciousness is dust and it steps out of a passive field of immanence. Thus consciousness creates dust.

"Dust is not a constant. There's no fixed quantity that has always been the same. Conscious beings make Dust they renew it all the time, by thinking, feeling and reflecting, by gaining wisdom and passing it on [1 p. 520]".

In microvita theory the relationship is more reciprocal than this but Pullman is vague on whether it is all one way. This is brought home when dust is being sucked out of the world, and with it consciousness. He introduces quantum theory into his novels too, thus the characters discuss 'shadows' or dust. When one asks 'What is Dust?' they get the following answer:

"We think it's some kind of elementary particle. Something quite different from anything discovered so far. But they're very hard to detect [1 p. 88]".

His humour at how to get such insights legitimated in the context of modern scientific terms is linked to a close description of shadows which is uncannily close to microvita:

"You know what? They're conscious. That's right. Shadows are particles of consciousness. You ever heard anything so stupid? No wonder we can't get our grant renewed [1 p. 89]."

His solution to working with such a new paradigm is to quote poetry, refer to the I Ching and create richly evocative alternate worlds. As in Smith's [36] description of postnormal science and Nicolescu's assertion that "In the quantum world, things happen differently" [9 p. 17] we find paradox and aporia at work in attempting to understand dustshadow-microvita theory. This is conveyed with minimum fuss for young readers thus:

'...capable of being in uncertainties, mysteries, doubts, without any irritable reaching after fact and reason -' You have to get into that state of mind. That's from the poet Keats, by the way [1 p. 89].

\section{Visual Arts}

Similarly the visual arts evokes a state of mindfulness that tunes the artist into what could be referred to as a microvital field of expanded presence where consciousness discerns new patterns in reality, as in the case of Andy Goldsworthy, or as in alternate realities as in the case of Marjorie Bussey. Goldsworthy's work involves nature and a dialogue with the elements. It is intuitively initiated and grows out of his ongoing relationship with a place. 
"I stop at a place or pick up a material because I feel there is something to be discovered. Here is where I can learn. I might have walked past or worked there many times. Some places I return to over and over again, going deeper - a relationship made in layers over a long time [57]."

This last statement - 'a relationship made in layers' captures something of what microvita theory brings to practice: That individual and collective experience is layered and in permanent flux. The Chaosmos of Dervin and Deleuze's analysis always allows for alternative readings immanent to context. Thus Goldsworthy, as a 'shaman', opens to a wider range of perceptual inference over time and always in situ.

"My perception of a place is often so frustratingly limited. The best of my work, sometimes the result of much struggle when made, appears so obvious that it is incredible I didn't see it before. It was there all the time [57]".

Similarly, his engagement with context is to see beneath the surface. This involves 'opening' to process.

"I need the shock of touch, the resistance of place, materials and weather, the earth as my source. I want to get under the surface. When I work with a leaf, rock, stick, it is not just the material in itself, it is an opening into the processes of life within and around it [57]".

At no time does Goldsworthy talk about spiritual matters in this work - it is intuitive alignment with space, and its potentiality within fields of energy. This alignment takes time, an inner knowing and connection. The artist is part of the creative space and works not just with positive space the materials present to the artist, but also negative space the space around the materials.

"The energy and space around a material are as important as the energy and space within. The weather - rain, sun, snow, hail, mist, calm - is that external space made visible. When I touch a rock, I am touching and working the space around it. It is not independent of its surroundings and the way it sits tells how it came to be there [57]".

This is a dialogue with what Sarkar would call the microvita that underpins all context and the artist as shaman enters such spaces/contexts and reveals potential. This requires superconscious mind to work in, though and around the dominant material constrains of context.

Bussey [58] describes a different entry into dialogue with context. For her, dominant habitus (identification with context) needs to be suspended for creative process to emerge. In the following interview she describes how she came to create a particular art work "Owl-Light".

It begins in a mundane context:

"I was sweeping the lounge room floor and musing on my recent paintings. On the wall hung a black and white drawing depicting an idea which initiated a painting based on an infinity principle entitled "In a dark, dark wood ... stood a dark, dark house ... stood a dark, dark room ... etc" until eventually a tiny little mouse was found".

The prosaic nature of the task enables her to enter the receptive space for creative emergence. The microvital reading is one, in this case, of opening to another dimension of reality, hidden beneath the surface of activity in the world of form. The owl as guide invites the artist as shaman to a different level of perception. Consciousness expands to attune to the mystery. Thus she continues:

"Contemplating this black and white artwork and sweeping absentmindedly I experienced a strange sort of waking dream. I found myself standing inside the drawing contemplating the dark, semi-abstract house in the wood".

"I was aware that I stood at a fence line, near a gate post which was in full colour, rough textured and old. And with a click in my head I perceived on the post a large white barn owl looking at me with large golden eyes. I could sense the softness of its downy feathers, my finger tips responding to the delight of the sensation."

"We looked into each others eyes for a moment in time. With a click in my head again, I was outside the frame, standing with the broom, sweeping the floor".

Later Bussey translated this experience into a dark and suggestive mixed media work. The viewer in turn in invited to enter the owl's space and discover for themselves something of what the artist initially experienced.

\section{Transformative Politics}

Such suggestive information comes not in bites but in transformative dislocation in which paradox and conscious translations of data, perceptual experience, energy and the like are reconceived (Deleuze and Guattari [8] would say deterritorialized) in a new and less confining construct. The nature of mind, intuitive or creative, is such that readings of reality are disrupted in order for new patterns to emerge. In politics too such dislocation can occur.

The Dalai Lama, for instance, refuses to be confined by the rules of international relations and has actively waged a peaceful engagement with China. Unlike the novelist or visual artist, his tools have not been materials drawn from the creative and intuitive domains of the superconscious mind but the even less tangible domain of spirit. The microvita here engage public opinion through presence and perseverance. The Dalai Lama has charisma but more importantly he is sustained by, and is able to communicate, a spiritual orientation and practice. His refusal to play by the rules of nation states is a powerful signal to the world of the possibilities before us if we step out of the dominant paradigm of state discourse. His example is a sign that superconscious mind is being linked with dominant discourses in order to reframe legitimacy and sovereignty. The Tibetan experience leads to a reframing of identity through his example.

The Dalai Lama understands that the micro and the macro are intimately connected and that shifts occur through a vibrational attunement across the spectrum of context. Tibet has ceased to be only a place on a map and become a place in the heart. We all have a Tibet within us that is denied - usually by dominant hegemonic structures with authority to impose upon our more sensitive aspirations order, the rule of law, and the promise of violence. To balance this 'disorder' he uses his practice to bring order and justice to his inner context and he extends this field microvitally 
through his example. Thus he notes: "By bringing about a certain inner discipline, we can undergo a transformation of our attitude, our entire outlook and approach to living [59 $\mathrm{p}$. $15]$ ".

A simple example of the power of this transformative politics is the Dalai Lama's encounter with a simple Mexican immigrant worker:

"One morning after his public lecture the Dalai Lama was walking along an outside patio on the way back to his hotel room, surrounded by his usual retinue. Noticing one of the hotel housekeeping staff standing by the elevators, he paused to ask her, 'Where are you from?' For a moment she appeared taken aback by this foreign looking man in the maroon robes and seemed puzzled by the deference of the entourage. Then she smiled and answered shyly, 'Mexico.' He paused briefly to chat with her a few moments and then walked on, leaving her with a look of excitement and pleasure on her face. The next morning at the same time, she appeared at the same spot with another of the housekeeping staff, and the two of them greeted him warmly as he got into the elevator. The interaction was brief but the two of them appeared flushed with happiness as they returned to work. Every day after that, they were joined by a few more of the housekeeping staff at the designated time and place, until by the end of the week there were dozens of maids in their crisp grayand-white uniforms forming a receiving line that stretched the length of the path that led to the elevator [59 p. 15-16]".

This is viral, rhizomic 'politics' at its best and demonstrates how changes in the fields of intention (Dalai Lama] and perception (the maid) lead to changes in the expression at other levels of reality. Was it the Dalai Lama's charm, the fact that the maid may have discovered he was a celebrity, or the fact that he exuded a happiness microvita? These are all questions that relate to different levels of perception, and all have merit in context and appear meaningless and irrelevant at other levels. Coherence and incoherence, order and chaos, thus play out at microvital levels of ordering that can be influenced consciously and unconsciously by a powerful mind whose deeper concerns and operations have been extended via the kind of 'inner discipline' the Dalai Lama encourages.

\section{CONCLUSION}

Microvita is an emergent concept rich with promise. Sarkar [2] suggested that it was a concept that would not reach its prime for centuries. Yet it is already a useful tool for assessing individual and cultural processes. It promises a higher degree of integration between materialist and spiritual discourses by proposing that we engage with the consciousness that flows between such constructs. Life happens between heaven and hell and is much more interesting than either (sorry Dante). The problem with language is that it constructs cages for the unwary. Noble captures the mood of our time however when he recently observed:

"All languages are prisons of culture as well as liberators of communication. We all need language to communicate, but our languages in turn cloud what we understand. There is no mystical oriental culture in which all our problems are solved. The point is rather that cross- cultural experience can help us break down our illusions [60 p. 137]".

This article has sought to place microvita in an intercivilizational context that straddles the creative territory posed by qualitatively different epistemological approaches to reality. The spiritual has been implicit in much of this encounter as consciousness has been central to the analysis. It has been proposed that microvita are ordered patterns of consciousness which behave differently according to context. Mind, strengthened and expanded, via what the Dalai Lama called 'inner discipline' and I take to be reflective practice such as meditation, contemplation, presence and stillness, can work with microvita in ways that help improve how we as human beings do business. Microvita theory challenges individuals and collectives to reclaim agency and engage in the innerouter work needed to transform current limitations inherent to context. This understanding opens up information science to deeper realities and to a range of information possibilities denied it by the parochial perspective promoted by Modernity's empirical and largely utilitarian tradition. In this lies the hope that transformative information, the subtle emanations of the Cosmos, will further liberate human perception from narrowness and foster more inclusive and equitable processes across the planet.

\section{ACKNOWLEDGEMENT}

The author wishes to acknowledge the assistance of Jeannette Oliver who prepared the figures for this paper and provided timely editorial assistance.

\section{REFERENCES}

[1] Pullman P. His Dark Materials III: The Amber Spyglass. London: Scholastic; 2000.

[2] Sarkar PR. Microvita in a Nutshell. Calcutta: AM Publications; 1991.

[3] Towsey M, Ghista Dhanjoo N. Towards a Science of Consciousness. In: Ghista DN, Ed. Proceedings of the Second Gauss Symposium: Biomedical and life phsyics. Munich, Germany: Verlag Viewveg; 1995. pp. 417-28.

[4] Deleuze G. Difference and Repetition. New York: Columbia University Press; 1994.

[5] Latour B. We have never been modern. Cambridge, Massachusetts: Harvard University Press; 1991.

[6] Law J, John U. Enacting the social. Econ Soc 2004; 33(3):390-410.

[7] Kaku M. Parallel Worlds: The science of alternative universes and our future in the cosmos. London: Allen Lane; 2005.

[8] Deleuze G, Felix G. A Thousand plateaus: Capitalism and schizophrenia. London \& New York: Continuum 1987.

[9] Nicolescu B. Manifesto of transdisciplinarity. Albany: State University of New York Press 2002.

[10] Towsey M, Ghista DN. The origins of mind. In: Ghista DN, Ed. Proceedings of the Second Gauss Symposium: Biomedical and life phsyics. Munich, Germany: Verlag Viewveg; 1995. pp. 335-46.

[11] Gautier R. The cosmic cycle of creation and microvita. In: Inayatullah S, Jennifer F, Eds. Transcending Boundaries: Prabhat rainjan sarkar's theories of individual and social transformation. Maleny, Australia: Gurukula Press; 1999. pp. 167-76.

[12] Inayatullah S. Understanding Sarkar: The indian episteme, macrohistory and transformative knowledge. Leiden Brill; 2002.

[13] Guha R. History at the limit of world-history. New York: Columbia University Press; 2002.

[14] Nandy A. Time Treks: The uncertain future of old and new despotisms. Ranikhet: Permanent Black 2007.

[15] Dervin B. On studying information seeking methodologically: The implications of connecting metatheory to method. Inf Process Manage 1999; 35(6): 727-50.

[16] Kari J, Reijo S. Towards a contextual model of information seeking on the Web. New Rev Inf Behav Res 2003; 4(1): 155-75. 
[17] Bates MJ. Information and Knowledge: An evolutionary framework for information science. Inf Res 2005; 10(4): http://InformationR.net/ir/10-4/paper239.html.

[18] Bjonnes R. Tantra and Veda: the untold story. Integral World [serial on the Internet]. 2010; http://www.integralworld.net/bjonnes1.html

[19] Bussey M. Neohumanism: Critical spirituality, tantra and education. In: Inayatullah S, Bussey, M. Milojevic I, Eds. Neohumanist Educational Futures: Liberating the pedagogical intellect. Taipei, Taiwan: Tamkang University Press; 2006. p. 80-95.

[20] Bussey M. Tantra as Episteme: A pedagogy of the future. Futures1998; 30(7): 705-16.

[21] Talbot M. The Holographic Universe. London: Harper Collins 1996.

[22] Randall L. Warped Passages: Unraveling the mysteries of the universe's hidden dimensions. New York: Harper Perennial 2006.

[23] Sarkar PR. Discourses on Tantra. Calcutta: Ananda Marga Publications 1993.

[24] Kari J. Conceptualizing the personal outcomes of information. Inf Res 2007; 12(2): http://InformationR.net/ir/12-2/paper292.html

[25] Adorno TW. Minima Moralia: Reflections on a damaged life. London: New Left Books; 1974.

[26] Herold K. An information continuum conjecture. Minds Machines 2003; 13(4): 553-66.

[27] Rowley J. What is Information? Inf Serv Use 1998; 18(4): 243-54.

[28] Giri AK. New horizons of social theory: Conversations, transformations and beyond. Jaipur: Rawat Publications; 2006.

[29] Bourdieu P. Intellectual field and creative project. In: Young MFD, Ed. Knowledge and Control: New Directions for the sociology of education. London: Collier Macmillan 1971; pp. 161-89.

[30] Rowley J. The Wisdom Hierarchy: Representations of the DIKW hierarchy. J Inf Sci 2006; 33(2): 163-80.

[31] Inayatullah S, Ed. The Causal Layered Analysis (CLA) Reader: Theory and case studies of an integrative and transformative methodology. Tamsui, Taiwan: Tamkang University Press 2004

[32] Floridi L. Open problems in the philosophy of information. Metaphilosophy 2004; 35(4): 554-82.

[33] Bussey M. Education for Liberation. In: Karlyle J, Towsey M, Eds. Understanding Prout: Essays of Sustainability and Transformation. Maleny, Australia: Proutist Universal 2010; pp. 77-104.

[34] Laszlo E. Macroshift: Navigating the transformation to a sustainable world. San Francisco: Berrett-Koehler Publishers; 2001.

[35] Loye D, Ed. The Great Adventure: Toward a fully human theory of evolution. Albany U.S: State University of New York Press; 2004.

[36] Smith T. Beyond Knowledge: A neo-research approach to climate change adaptation. In: Martin J, Ed. Climate Change Responses Across Regional Australia: Social Learning and Adaptation. Victoria: VURRN Press 2010.
[37] Deleuze G, Felix G. What is Philosophy? New York: Columbia University Press 1994.

[38] Semetsky I. Deleuze, Education and Becoming. Rotterdam/Taipei: Sense Publishers; 2006.

[39] Bussey M. Six Shamanic Concepts: Exploring the between in futures work. Foresight 2009; 11(2): 29-42.

[40] Inayatullah S. Six Pillars: Futures thinking for transforming. Foresight 2008; 10(1):4-21.

[41] Inayatullah S. Alternative Futures: Methodology, society, macrohistory and the long-term future. In: Feng C-K, Ed. Taipai: Taiwan International Exchange Committee: Tamkang University 2000.

[42] Dervin B. Chaos, Order and Sense-Making: A proposed theory for information design. In: Jacobson R, Ed. Information Design. Cambridge, Mass.: MIT Press 1999; pp. 35-57.

[43] Flood RL. Rethinking the Fifth Discipline: Learning within the unknowable. London \& New York: Routledge; 1999.

[44] Capra F. The Turning Point: Science, society, and the rising culture. New York: Bantam; 1984.

[45] Sheldrake R. The Sense of Being Stared at: And other aspects of the extended mind. Boulder: Three Rivers Press; 2004.

[46] Greene M. Variations on a Blue Guitar: The Lincoln Center Institute Lectures on Aesthetic Education. New York \& London: Teachers College Press 2001.

[47] Stevens W. The Man with the Blue Guitar. The collected poems New York: Vintage Books 1982.

[48] Deleuze G. Two Regimes of Madness: Texts and interviews 19751995. Los Angeles, CA: Semiotext(e); 2006.

[49] Hicks E, Jerry H. The Law of Attraction: The basics of the teachings of Abraham. Carlsbad, California: Hay House; 2006.

[50] Stone H, and Stone S. Embracing Ourselves: The voice dialogue manual. Novato, CA: New World Library 1989.

[51] Tolle E. A New Earth: Awakening to your life's true purpose. London: A Plume Book 2005.

[52] Muecke S. Ancient \& Modern: Time, culture and indigenous philosophy. Sydney: UNSW Press; 2004.

[53] Sheldrake R. The Presence of the Past: morphic resonance and the habits of nature. London: Collins 1988.

[54] Kornfeld A, Elias B. Mind Over Chocolate. Time Magaizine 2009: 35

[55] Carmody I. Obernewtyn. New York: Penguin; 1993.

[56] Pullman P. His Dark Materials Trilogy. London: Scholastic 2008.

[57] Goldsworthy A. Andy Goldsworthy: A collaboration with nature. New York: Harry N. Abrams 1990.

[58] Bussey M. My Owl Vision. [Letter]. In press 2009.

[59] Lama D, Howard CC. The Art of Happiness: A handbook for living. Sydney: Hachette Australia 1998

[60] Noble D. The Music of Life: Biology beyond genes. Oxford: Oxford University Press 2006.

\begin{tabular}{lll}
\hline Received: March 30, 2010 & Revised: May 07, 2010 Accepted: May 07, 2010
\end{tabular}

(C) Marcus Bussey; Licensee Bentham Open.

This is an open access article licensed under the terms of the Creative Commons Attribution Non-Commercial License (http://creativecommons.org/ licenses/by-nc/3.0/) which permits unrestricted, non-commercial use, distribution and reproduction in any medium, provided the work is properly cited. 